\title{
Prognostic factors for surgical outcome and survival in 447 women treated for advanced (FIGO-stages III-IV) epithelial ovarian carcinoma
}

\author{
INGIRÍDUR SKÍRNISDÓTTIR ${ }^{1}$ and BENGT SORBE ${ }^{2}$ \\ ${ }^{1}$ Department of Women's and Children's Health, Obstetrics and Gynecology, University Hospital, Uppsala; \\ ${ }^{2}$ Department of Gynecological Oncology, Örebro University Hospital, Örebro, Sweden
}

Received October 9, 2006; Accepted November 24, 2006

\begin{abstract}
The objectives of this population-based, retrospective study, was to find predictive factors for surgical outcome and long-term survival in 447 patients with epithelial ovarian cancer in FIGO-stages III-IV treated during 19751993. The median overall survival rate of this series was 18 months, the 5-year cancer-specific survival rate was $18 \%$, and the 5-year overall survival rate, $16 \%$. In a logistic regression analysis, type of surgeon was the strongest $(\mathrm{P}=0.006)$ predictive factor for surgical outcome after the age of the patient. The optimal debulking rate was $36 \%$ for gynecologic oncologists, $29 \%$ for general gynecologists, $24 \%$ for combined gynecologist and obstetrician with the third level of specialization, and 4\% for general surgeons. Optimal debulking (no visible tumor or residual tumor $<2 \mathrm{~cm}$ ) was achieved in $26 \%$ of the cases. Predictive factors of the outcome of cytoreduction were FIGO-stage $(\mathrm{P}=0.007)$, histological subtype $(\mathrm{P}=0.016)$, and tumor grade $(\mathrm{P}=0.046)$ in univariate analyses. In a Cox multivariate analysis the most important prognostic factor for overall survival was the amount of residual cancer $(\mathrm{P}=0.000001)$ before age, grade and stage. Therefore, to achieve optimal surgical outcome and optimal overall survival rate the primary surgery of advanced ovarian cancer should be performed by gynecologic oncologists or by gynecologists specially trained in gynecologic cancer surgery.
\end{abstract}

\section{Introduction}

Epithelial ovarian cancer is still the leading cause of mortality among women with gynecologic malignancies. At diagnosis $>60 \%$ of the women have advanced disease and despite several improvements in the management of this disease, the

Correspondence to: Dr Ingirídur Skírnisdóttir, Department of Women's and Children's Health, Obstetrics and Gynecology, University Hospital, Akademiska sjukhuset, SE-751 85 Uppsala, Sweden

E-mail: ingiridur.skirnisdottir@kbh.uu.se

Key words: ovarian carcinoma, prognostic factors, surgical outcome, survival mortality is still high with only a $30 \%$ survival rate at 5 years $(1,2)$. The aim of the primary cytoreductive surgery is removal of the tumor burden and relief of symptoms caused by the tumor.

The size of the residual tumor is one of the most important prognostic factors and the only one the surgeon can influence $(3,4)$. However, general agreement on the amount of residual tumor that constitutes optimal cytoreduction is lacking. In two separate GOG-trials there was no clear-cut advantage of a $1-\mathrm{cm}$ versus a 2 -cm cutoff in separating optimally from suboptimally resected tumors (5). It is not completely understood whether the intrinsic biological behavior of the tumor or the skill of the surgeon is the main determinant of optimal cytoreduction. Several studies $(2,6,7-12)$ have been performed to find preoperative methods or models on the basis of imaging, amount of ascites, serum marker CA-125 or molecular tissue markers that can predict the surgical outcome. As the prediction rates in these studies have a wide range, it is not clear whether the results are dependent on patient selection or type of hospital. However, the prognostic importance of the quality of the primary surgery is shown by higher rates of optimal cytoreduction and also improved survival when surgery is performed by sub-specialized surgeons $(4,13)$.

This population-based, retrospective study encompassed patients who underwent primary cytoreductive surgery for epithelial ovarian cancer in FIGO-stages III-IV. The aims of the study were to find predictive factors for successful cytoreduction and to study the relationship between the experience of the surgeon and the type of hospital where the surgery was performed and the outcome of the patients. Prognostic factors for survival were also studied in this series of patients.

\section{Materials and methods}

Patients. A total of 447 patients with stage III or IV epithelial ovarian cancer (EOC), who underwent primary surgery between 1975 and 1993, and who postoperatively were referred to the Department of Gynecological Oncology, Örebro University Hospital, were included in the study. Data of this study were retrieved from a regional database of all gynecologic cancers diagnosed in the Örebro medical region and from a secondary review of all individual patient records 
at the Department of Gynecological Oncology. The characteristics of the patients are presented in Table I. The mean age of patients was 62.4 years and the range was $21-84$ years.

History of diagnosis. The diagnosis of ovarian cancer was primarily suspected in the majority of the patients $(88 \%)$ because of the presenting signs and symptoms, but in the remaining patients $(12 \%)$ it was confirmed at the surgery which was performed due to other preliminary diagnoses. The patients were referred to the gynecological centers by general medical practitioners in $37 \%$ of the cases, and by outside gynecologists and private gynecologists in $18 \%$ and $5 \%$, respectively. The remaining $40 \%$ of the patients were referred by other types of specialists (mostly general surgeons). However, the area of preoperative imaging for diagnosis was not the field of this study.

Organization of the hospitals and competence of the surgeons. All patients underwent a primary surgical exploration with the aims of diagnosing, staging, and surgically reducing the tumor volume. There were seven referring gynecological centers in the region. A total of 323 patients out of the 447 patients underwent primary surgery at the gynecological departments in three different medical center hospitals (category 1 and 2) and the remaining 124 patients at gynecological departments at community hospitals (category 3 ) or at departments of surgery. Gynecologic oncologists, representing the highest level of specialization among the surgeons, were available at two of the medical center hospitals (Örebro and Karlstad). Gynecologists with the second level of specialization for primary surgery were represented at the third medical center hospital (Eskilstuna). In the remaining cases the primary surgery was performed by gynecologist/ obstetricians with the third level of specialization (with limited surgical experience of gynecological cancer) or by general surgeons at community hospitals.

Postoperative chemotherapy and follow-up. All patients were referred to the highly specialized gynecologic oncology center, 4-6 weeks after the primary surgery, for final staging and classification of the tumor and for drawing up a treatment plan. The chemotherapy administered during the time period studied was highly standardized and contained a platinum agent (cisplatin $75 \mathrm{mg} / \mathrm{m}^{2}$ or carboplatin AUC 5-6) mainly in combination with an anthracyclin (doxorubicin or epirubicin $75 \mathrm{mg} / \mathrm{m}^{2}$ ). According to the routine during the time period studied, 10 courses of chemotherapy were administered every four weeks. The mean follow-up time of the complete series was 31 months and the range was 1-241 months. However, the mean follow-up time for patients living without recurrent disease was 105 months. No patients were lost to follow-up

Sampling and preservation of ovarian cancer tissue. The histopathological specimens were reviewed and, if necessary, reclassified at the Department of Pathology, Örebro University Hospital. The primary evaluations of the histopathological specimens were made at three referring departments of pathology in the region serving the seven referring gyneco-
Table I. Patient characteristics $(n=447)$.

Age (range)

$62.4(21-84)$

FIGO-stage: number (\%)

III

$291(65 \%)$

IV

$156(35 \%)$

Residual tumor: number $(\%)$

None

$39(9 \%)$

$<2 \mathrm{~cm}$

$80(18 \%)$

$\geq 2 \mathrm{~cm}$

$301(67 \%)$

Missing

Histology: number (\%)

Serous

$312(70 \%)$

Mucinous

Endometrioid

Clear cell

Anaplastic

Tumor grade: number (\%)

G1

G2

$152(34 \%)$

G3

$224(50 \%)$

Not graded

Type of hospital: number (\%)

Category 1

$124(28 \%)$

Category 2

Category 3

$124(28 \%)$

logical departments. The FIGO-stage, histopathology, and tumor grade distributions are presented in Table I.

Statistical analyses. The Pearson's Chi-square test was used for testing proportional differences in univariate analyses. The survival curves were generated by using the KaplanMeier technique (14) and differences between these curves were tested by the log-rank test. For multivariate analyses the Cox proportional hazard regression model (15) was used with overall survival as the end point. All tests were two-sided and the level of statistical significance was $P \leq 0.05$. The Statistica 6.0 (StatSoft $^{\mathrm{TM}}$ ) statistical package for personal computers was used for the analyses.

\section{Results}

Hospitals and surgeons. In total, 323 patients out of the 447 underwent primary surgery at the departments of gynecology at the three medical center hospitals, and the remaining 124 patients at the departments of gynecology or surgery at the community hospitals. Gynecologic oncologists, representing the highest level of competence among the surgeons, were represented in two of the medical center hospitals, and were involved in the surgical procedures of 137 patients (31\%). Primary surgery for nearly half of the patients, 195 cases (44\%), was performed by non-specialized gynecologists, however. In 38 cases (8\%) the initial surgery was performed by gynecologists/obstetricians with limited surgical experience. 
Table II. The outcome of the primary cytoreductive surgery.

\begin{tabular}{|c|c|c|c|c|}
\hline & $\begin{array}{l}\text { No residual tumor } \\
\qquad(\mathrm{n}=39)(9 \%)\end{array}$ & $\begin{array}{l}\text { Residual tumor } \\
\quad<2 \mathrm{~cm} \\
(\mathrm{n}=80)(18 \%)\end{array}$ & $\begin{array}{l}\text { Residual tumor } \\
\quad \geq 2 \mathrm{~cm} \\
(\mathrm{n}=301)(67 \%)\end{array}$ & $\chi^{2}$ test \\
\hline \multicolumn{5}{|l|}{ Histology } \\
\hline Serous & $21(54 \%)$ & $60(75 \%)$ & $211(70 \%)$ & \\
\hline Mucinous & $7(18 \%)$ & $3(4 \%)$ & $26(9 \%)$ & \\
\hline Endometrioid & $11(28 \%)$ & $8(10 \%)$ & $40(13 \%)$ & \\
\hline Clear cell & 0 & $4(5 \%)$ & $10(3 \%)$ & \\
\hline \multirow[t]{2}{*}{ Anaplastic } & 0 & $5(6 \%)$ & $14(5 \%)$ & \\
\hline & & & & 0.016 \\
\hline \multicolumn{5}{|l|}{ Tumor grade } \\
\hline G1 & $8(21 \%)$ & $11(14 \%)$ & $22(7 \%)$ & \\
\hline $\mathrm{G} 2$ & $16(41 \%)$ & $25(31 \%)$ & $101(34 \%)$ & \\
\hline G3 & $15(39 \%)$ & $40(50 \%)$ & $157(52 \%)$ & \\
\hline \multirow[t]{2}{*}{ Not graded } & 0 & $4(5 \%)$ & $21(7 \%)$ & \\
\hline & & & & 0.046 \\
\hline \multicolumn{5}{|l|}{ FIGO-stage } \\
\hline III & $25(64 \%)$ & $65(81 \%)$ & $188(62 \%)$ & \\
\hline \multirow[t]{2}{*}{ IV } & $14(36 \%)$ & $15(19 \%)$ & $113(38 \%)$ & \\
\hline & & & & 0.007 \\
\hline \multicolumn{5}{|l|}{ Type of hospital } \\
\hline Category 1 & $12(31 \%)$ & $26(33 \%)$ & $80(27 \%)$ & \\
\hline Category 2 & $18(46 \%)$ & $40(50 \%)$ & $136(45 \%)$ & \\
\hline \multirow[t]{2}{*}{ Category 3} & $9(23 \%)$ & $14(18 \%)$ & $85(28 \%)$ & \\
\hline & & & & 0.384 \\
\hline \multicolumn{5}{|l|}{ Type of surgeon } \\
\hline Gyn. oncologist & $15(39 \%)$ & $34(44 \%)$ & $88(29 \%)$ & \\
\hline Gynecologist & $22(58 \%)$ & $34(44 \%)$ & $139(46 \%)$ & \\
\hline Gynecologist $t^{\mathrm{a}}$ & $1(3 \%)$ & $8(10 \%)$ & $29(10 \%)$ & \\
\hline \multirow[t]{2}{*}{ General surgeon } & 0 & $2(3 \%)$ & $44(15 \%)$ & \\
\hline & & & & 0.002 \\
\hline
\end{tabular}

Table III. Surgical outcome versus type of surgeon.

\begin{tabular}{lcccc}
\hline $\begin{array}{l}\text { Surgical } \\
\text { outcome }\end{array}$ & $\begin{array}{c}\text { Gynecologic } \\
\text { oncologist }\end{array}$ & $\begin{array}{c}\text { General } \\
\text { gynecologist }\end{array}$ & Gynecologist $^{\mathrm{b}}$ & $\begin{array}{c}\text { General } \\
\text { surgeon }\end{array}$ \\
\hline 0 & $15(11 \%)$ & $22(11 \%)$ & $1(3 \%)$ & 0 \\
$<2 \mathrm{~cm}$ & $34(25 \%)$ & $34(17 \%)$ & $8(21 \%)$ & $2(4 \%)$ \\
$\geq 2 \mathrm{~cm}$ & $88(64 \%)$ & $139(71 \%)$ & $29(76 \%)$ & $44(96 \%)$ \\
\hline
\end{tabular}

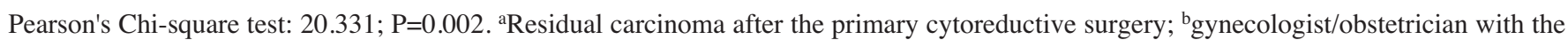
third level of specialization.

Finally, in 46 cases (10\%) the patients were operated on by general surgeons. The surgeons were not classified with regard to competence in 31 cases $(7 \%)$.

Results of the surgical procedures. At the end of the cytoreductive surgery (Table I), only 39 patients $(9 \%)$ had no gross residual disease, 80 patients $(18 \%)$ had gross residual tumors $<2 \mathrm{~cm}$ at the largest diameter and 301 patients $(67 \%)$ had residual disease $\geq 2 \mathrm{~cm}$. Thus, optimal cytoreduction with no macroscopic disease or tumors $<2 \mathrm{~cm}$ was achieved in 119 out of the 447 patients (27\%). In 27 cases (6\%) residual carcinoma was not assessed. All patients underwent primary 
Table IV. Type of surgeon versus outcome of the primary cytoreductive surgery.a

\begin{tabular}{lcccrr}
\hline Variable & $\beta$ & SE & Odds ratio & Wald stat & P value \\
\hline Age & 0.027 & 0.009 & 1.028 & 8.382 & 0.004 \\
Stage (IV vs III) & 0.527 & 0.261 & 1.693 & 4.066 & 0.044 \\
Grade (2-3 vs 1) & 0.825 & 0.360 & 2.281 & 5.246 & 0.022 \\
Surgeon $^{\text {b }}$ & 2.065 & 0.751 & 7.884 & 7.566 & 0.006 \\
\hline
\end{tabular}

${ }^{\mathrm{a} L o g i s t i c ~ r e g r e s s i o n ~ a n a l y s i s . ~}{ }^{\mathrm{b}}$ General surgeon versus various types of gynecologic surgeons.

Table V. Tumor characteristics versus survival status.

\begin{tabular}{lccc}
\hline Variables & $\begin{array}{c}\text { Living } \\
(\mathrm{n}=43)(\%)\end{array}$ & $\begin{array}{c}\text { Deceased due to disease } \\
(\mathrm{n}=382)(\%)\end{array}$ & $\begin{array}{c}\text { Total } \\
(\mathrm{n}=446)(\%)\end{array}$ \\
\hline FIGO-stage & & & \\
III & $34(79 \%)$ & $243(64 \%)$ & $290(65 \%)$ \\
IV & $9(21 \%)$ & $139(36 \%)$ & $156(35 \%)$
\end{tabular}

$\begin{array}{lc}\text { Histology } & \\ \text { Serous } & 28(65 \%) \\ \text { Mucinous } & 4(9 \%) \\ \text { Endometrioid } & 8(19 \%) \\ \text { Clear cell } & 0 \\ \text { Anaplastic } & 3(7 \%)\end{array}$

$$
\begin{gathered}
270(71 \%) \\
31(8 \%) \\
53(14 \%) \\
14(4 \%) \\
14(4 \%)
\end{gathered}
$$

0.04400

\section{Tumor grade}

$\begin{array}{lccc}\text { G1 } & 13(30 \%) & 25(7 \%) & 42(7 \%) \\ \text { G2 } & 14(33 \%) & 136(36 \%) & 152(34 \%) \\ \text { G3 } & 15(35 \%) & 193(51 \%) & 223(52 \%) \\ \text { Not graded } & 1(2 \%) & 28(7 \%) & 21(7 \%)\end{array}$

$\begin{array}{cr}0 & 8(20 \%) \\ <2 \mathrm{~cm} & 19(46 \%) \\ \geq 2 \mathrm{~cm} & 14(34 \%)\end{array}$

$$
\begin{gathered}
28(8 \%) \\
55(15 \%) \\
276(77 \%)
\end{gathered}
$$$$
39(9 \%)
$$

aPearson's Chi-square test.

surgical exploration with the objectives being to diagnose, to stage, and to reduce the tumor volume. The result of the maximum surgical effort was significantly $(\mathrm{P}=0.0002)$ associated with the age of the patients.

Predictive factors related to surgical outcome. Tables II and III demonstrate the univariate analyses of some intrinsic factors of the ovarian carcinomas, such as FIGO-stage, histology, grade, resectability, and other external factors, e.g. the competence and experience of the surgeon and the type of hospital. Women with serous papillary tumors were less likely to achieve complete cytoreduction. Only 21 out of 292 (7\%) seropapillary carcinomas could be completely resected compared to 7 out of 36 (19\%) of the mucinous tumors, and 11 out of $59(19 \%)$ of the endometrioid carcinomas.

Tumor grade was statistically significantly $(\mathrm{P}=0.046)$ associated with the surgical outcome and it was shown that grade 3 tumors were more frequent in cases with residual tumors $\geq 2 \mathrm{~cm}(52 \%)$ compared with tumors completely resected $(39 \%)$. There was a highly significant $(\mathrm{P}=0.0001)$ association between type of histology and tumor grade. Thus, $52 \%(163 / 312)$ of serous carcinomas were of grade 3 compared to only $22 \%(8 / 37)$ of the mucinous carcinomas. However, in this series, tumor stage (FIGO III or IV) and type of histology were not significantly $(\mathrm{P}=0.268)$ associated with each other, probably due to the fact that only stage III and IV 
Table VI. Type of hospital versus the overall survival probability. ${ }^{\mathrm{a}}$

\begin{tabular}{lcccrc}
\hline Variable & $\beta$ & SE & Exp B & Wald stat & P value \\
\hline Age & 0.018 & 0.005 & 1.018 & 16.054 & 0.000100 \\
Stage (IV vs III) & 0.230 & 0.105 & 1.350 & 8.242 & 0.004000 \\
Grade (2-3 vs 1) & 0.588 & 0.194 & 1.801 & 9.175 & 0.002000 \\
Residual tumor $^{\mathrm{b}}$ & 0.677 & 0.123 & 1.968 & 30.480 & 0.000001 \\
Hospitalc $^{c}$ & 0.132 & 0.111 & 1.141 & 1.403 & 0.236000 \\
\hline
\end{tabular}

${ }^{\mathrm{a}}$ Cox proportional hazard analysis. ${ }^{\mathrm{b}}$ Residual tumor $\geq 2 \mathrm{~cm}$ versus $<2 \mathrm{~cm}$. ${ }^{\mathrm{c}}$ Community hospital versus central and university hospital.

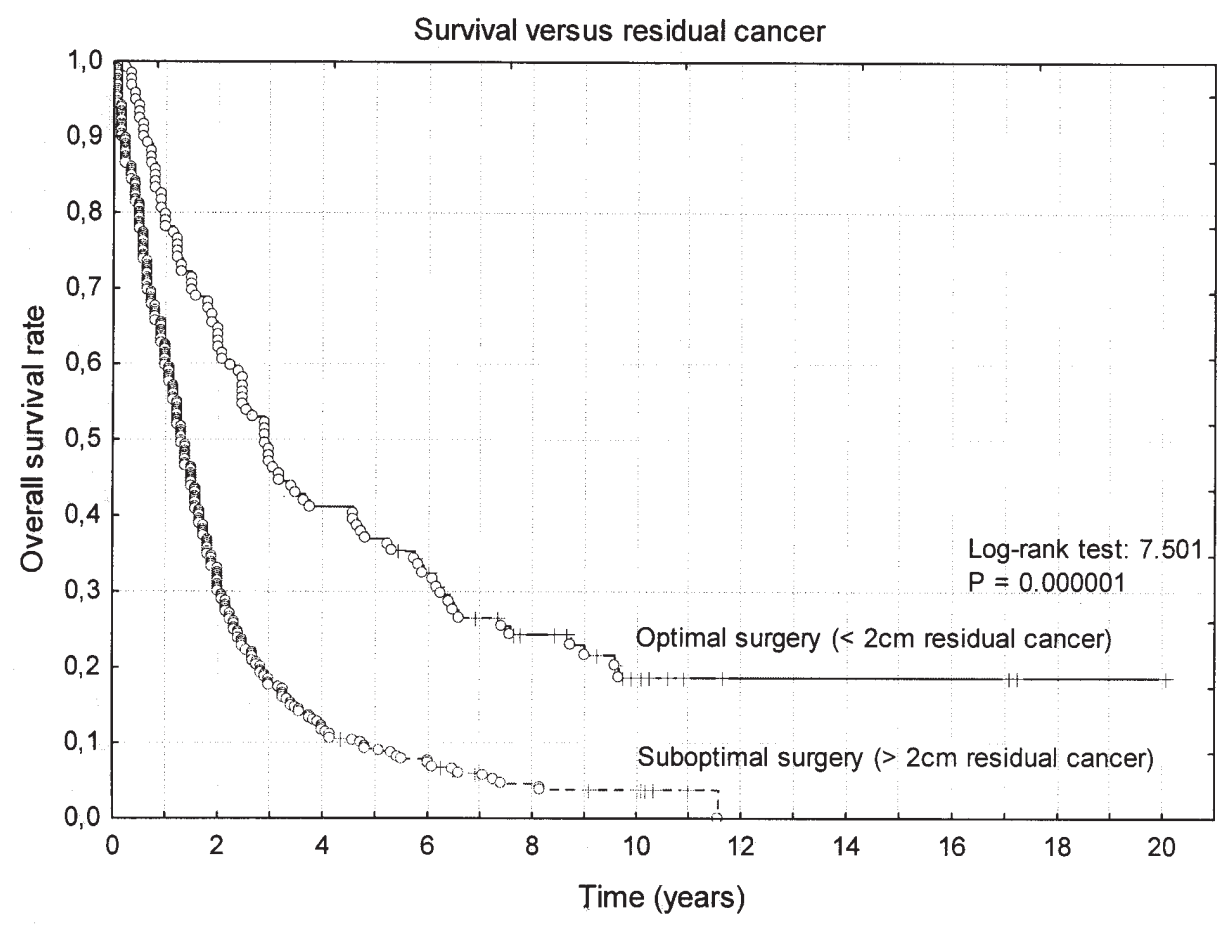

Figure 1. Overall survival rate (Kaplan-Meier) versus outcome of the primary cytoreductive surgery.

tumors were represented. Tumor stage (FIGO III or IV) and tumor grade were not associated $(\mathrm{P}=0.139)$ in the present study.

On the other hand, FIGO-stage was associated with the competence of the surgeon. The most striking finding was that only $8 \%(23 / 277)$ of the stage III patients underwent primary surgery performed by general surgeons compared to $18 \%(25 / 141)$ of the stage IV patients. Furthermore, the type of surgeon had great impact on the results of the maximum surgical effort (Table III). The carcinomas could be completely removed or reduced to a largest diameter of $<2 \mathrm{~cm}$ in $36 \%$ of the cases operated on by a gynecologic oncologist, in $29 \%$ of the cases by a non-specialized gynecologist, in $24 \%$ if the surgeon was a gynecologist/obstetrician, and in only $4 \%$ if the surgery was performed by a general surgeon. In a multivariate logistic regression analysis, type of surgeon was a highly significant $(\mathrm{P}=0.006)$ and independent predictive factor with regard to the surgical outcome of the primary cytoreduction after correction for the age of the patient, tumor stage and tumor grade (Table IV). However, distribution of the FIGO-stages and the surgical outcome were not associated with type of hospital.

Type of surgical procedure. Type of surgery was related to both type of surgeon $(\mathrm{P}=0.0001)$ and category of hospital $(\mathrm{P}=0.0024)$. The standard primary surgery consisted of total abdominal hysterectomy and bilateral salpingo-oophorectomy, partial or total omentectomy, appendectomy, and multiple biopsies of the peritoneal surfaces. In 132 cases $(30 \%)$ bilateral salpingo-oophorectomy, total abdominal hysterectomy and in most cases omentectomy were performed. In 6 cases $(1 \%)$ the same type of surgical procedure was used with the exception that only unilateral salpingo-oophorectomy was performed. In 135 patients (30\%), usually recruited from the first half of the period studied, the surgical procedure consisted of bilateral salpingo-oophorectomy and omentectomy, and in 44 patients $(10 \%)$ unilateral salpingooophorectomy with omentectomy was performed. Lastly, in 105 cases $(25 \%)$ the primary surgery consisted of explorative laparotomy and biopsies of the primary tumor or of metastases 


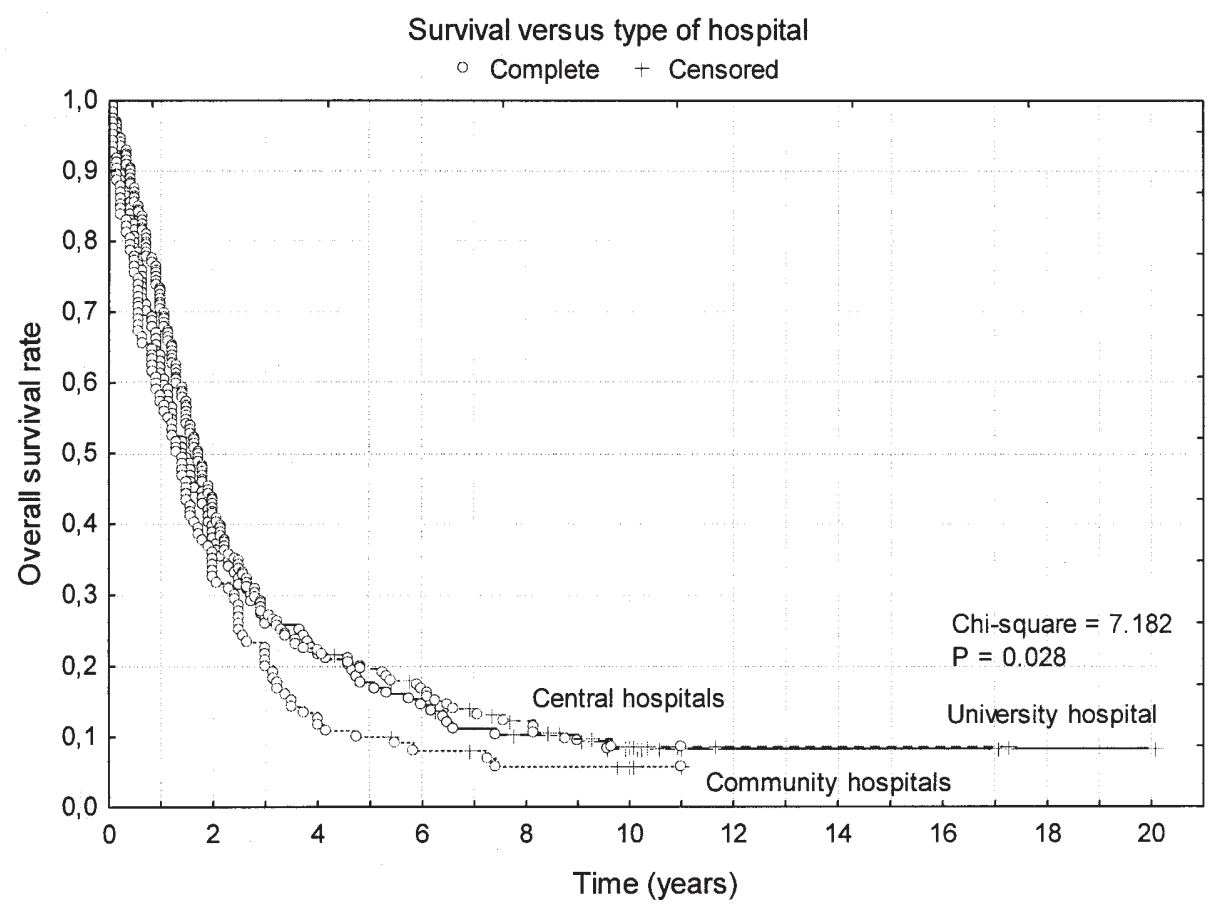

Figure 2. Overall survival rate (Kaplan-Meier) versus type of hospital for the primary cytoreductive surgery.

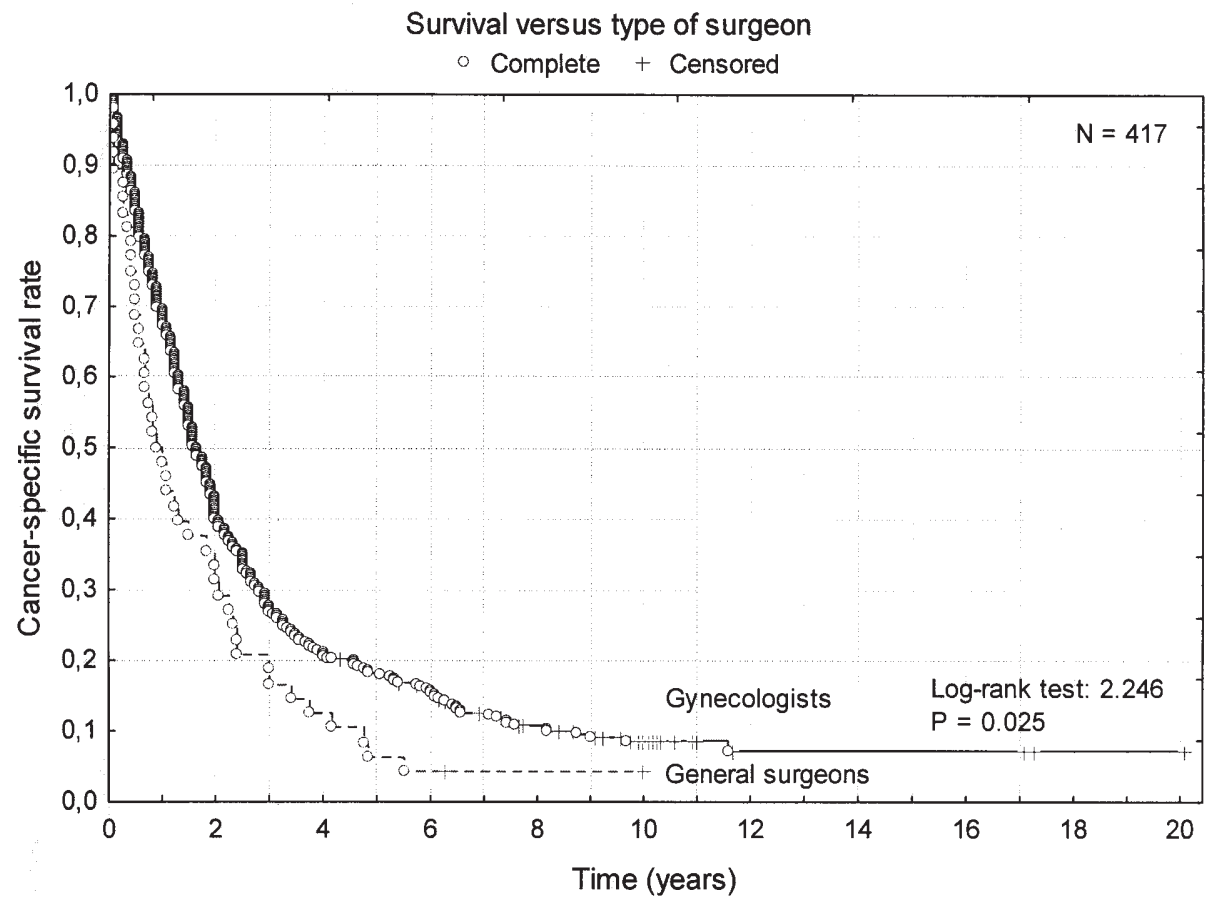

Figure 3. Cancer-specific survival rate (Kaplan-Meier) versus type of surgeon performing the primary cytoreductive surgery.

of the oment. In 23 cases (5\%) information with regard to the type of surgery was not complete.

Survival. In this series of patients with stage III-IV disease, the median overall survival rate was 18 months, the cancerspecific survival rate, $18 \%$ and the overall survival rate $16 \%$ at 5 years. In stage III the overall survival rate was $20 \%$ and in stage IV, $10 \%$. Forty-three patients (10\%) were living with or without disease at the last follow-up, and 382 patients $(85 \%)$ were deceased due to the disease. The characteristics of the two groups of patients are presented in Table V. Thus, patients who were alive were more frequently found in FIGO-stage III (79\%), with tumors of grade 1 or $2(63 \%)$ and with residual carcinoma $<2 \mathrm{~cm}$ after primary cytoreduction $(66 \%)$. The 5-year survival rate of patients with optimally debulked tumors was $21 \%$. Survival curves according to 
Kaplan-Meier presenting overall survival versus residual disease are shown in Fig. 1 and versus type of hospital in Fig. 2. Cancer-specific survival versus type of surgeon is shown in Fig. 3. However, in multivariate analysis (Table VI) the overall survival rate was associated with the age of the patient, tumor stage, tumor grade, and residual tumor, but not with type of hospital.

Prognostic factors in multivariate analysis. In multivariate analyses (Cox proportional hazard regression), with overall survival as endpoint, the age of the patient, tumor stage, tumor grade and the outcome of the primary surgery (residual tumor) were significant and independent prognostic factors. However, after correction for these factors, type of hospital was not a significant $(\mathrm{P}=0.236)$ factor. General surgeon was an unfavorable prognostic factor for overall survival $(\mathrm{P}=0.034)$. For cancer-specific survival rate, both type of surgeon and type of hospital were significant prognostic factors. Patients treated by general surgeons were significantly $(\mathrm{P}=0.013$ ) older (mean 66.5 years) than patients treated by various types of gynecological surgeons (mean 62.0 years).

\section{Discussion}

The long-term prognosis for patients with advanced ovarian cancer (FIGO-stages III-IV) treated in the pre-taxane era between 1975 and 1994 was poor. There were only 43 longterm survivors out of 447 patients $(10 \%)$ in our study (16). During this period the primary cytoreductive surgery was performed by surgeons with various competencies in both expert centers and in other types of hospitals without any centralization or fully-trained gynecologic tumor surgeons available. The surgeon was a gynecologic oncologist at the primary surgery in $31 \%$ of cases and the results from our study are consistent with the studies of Averette et al (17) and Nguyen et al (18), where only $25 \%$ and $21 \%$ of the ovarian cancer patients had access to such surgical competence. In the present study, optimal debulking (no visible tumor or residual tumor $<2 \mathrm{~cm}$ ) was achieved in $26 \%$ of the cases. A recently published meta-analysis by Bristow et al, including nearly 7,000 patients with stage III and IV ovarian cancer in 81 cohorts between 1989 and 1998, found that the majority of the studies (79\%) used a criterion of $<2 \mathrm{~cm}$ residual tumor for definition of optimum cytoreductive surgery (8). In eight of the studies, including $>200$ patients, the optimum cytoreduction ranged from $31-100 \%$. Each $10 \%$ increase in the optimum cytoreduction was associated with a $6 \%$ increase in the median survival of all studies.

Tumor biology is important for patient outcome, but it is difficult to quantify in a clinically useful manner. Some authors believe that the improved survival after optimum cytoreduction is not necessarily due to the surgical procedure itself, but due to biologically less aggressive tumors, explaining successful cytoreduction $(6,8,19,20)$. Predictive factors of the outcome of cytoreduction in this study were FIGO-stage, histological subtype, and tumor grade in the univariate analysis. These findings are comparable with those reported in a study by Eltabakh et al where clinical and molecular factors predictive for the outcome of cytoreduction were evaluated (6). Women with serous papillary histology were less likely to achieve a complete cytoreduction than women with non-serous histological subtypes. Women with tumors in stage IIIC and stage IV were also unfavorable compared with women with tumors in substages IIIA and IIIB regarding optimum cytoreduction. P53 expression was the only molecular factor out of eight biomarkers evaluated that was predictive of complete cytoreduction. Naik et al found in a study including 53 patients with tumors in stages IIA-IIIC, who underwent complete cytoreduction, that tumor grade was the only independent predictive factor (21). In the present study, the optimum surgical outcome was associated with both intrinsic tumor factors (stage, histology, and grade) and with external factors, e.g. the level of competence of the surgeon, the latter factor being the only one that could be influenced.

The importance of the type of surgeon for the outcome of patients with advanced ovarian cancer is shown in the present study. Thus, the total optimum debulking rate was $36 \%$ for gynecologic oncologists, $29 \%$ for general gynecologists, $24 \%$ for gynecologist/obstetricians, and $4 \%$ for general surgeons. Our study is consistent with work done in other countries showing that the specialty of the surgeon influences outcome. In a study from Scotland total optimum debulking rate (cut-off value $<2 \mathrm{~cm}$ ) was found in $36 \%$ of the cases operated on by a gynecologic oncologist, in $29 \%$ of cases operated on by a general gynecologist, and lastly in $12 \%$ of the cases when surgery was performed by a general surgeon (22). In this study, the type of surgery performed was strongly related to both type of surgeon and type of hospital, but the optimum debulking rate was not related to type of hospital. These somewhat conflicting results could be explained by the fact that gynecologic oncologists were represented in only two out of the three category 1-2 hospitals and secondly by the fact that different surgical outcomes could have been coded with the same number, since these codes were used for the initial surgical procedure. A study by Kaern et al, including 51 patients with stage III tumors, showed that the volume of the residual tumor $(<1 \mathrm{~cm})$ was the most important predictor for patient outcome (23). These results are in agreement with those of our study. The overall 5-year survival rate was $21 \%$ for optimally debulked patients in our series after post-operative platinum-based chemotherapy. Engel et al evaluated a series of 3,750 patients with stage III-IV tumors during a 20-year period from 1978 to 1997 with regard to prognostic factors for survival (24). Overall survival for 267 patients with radically debulked stage III tumors was $17 \%$ and for 385 patients with residual tumors $<2 \mathrm{~cm} 25 \%$ and for 41 patients radically debulked in stage IV the survival was $3 \%$. However, survival for 117 patients with tumors in stage IV and with residual tumors $<2 \mathrm{~cm}$ was $8 \%$. In conclusion, a prolongation in short-term survival was found for patients in FIGO-stages III-IV, but no improvement in the long-term survival rate was seen after 5 or 10 years. The main reason for improved short-term survival appeared to be an increased proportion of optimal cytoreductive operations in combination with more effective chemotherapy.

However, many authors have reported higher rates of optimal cytoreduction and higher rates of 5-year survival. Chi et al reported a 5-year survival rate of $\sim 50 \%$ for the $25 \%$ 
of patients with stage III disease where optimal cytoreduction $(<1 \mathrm{~cm})$ was achieved (25). In another study by Polverino et al, age, histopathological type, and the amount of residual tumor after primary surgery were predictors for overall survival (26). The 5-year survival rates in their series were $65 \%$ in stage III and $58 \%$ in stage IV.

The impact of type of surgeon for survival in our series was demonstrated (Fig. 3) by a $10 \%$ cancer-specific survival rate if the primary surgery was performed by a gynecologist/ obstetrician or a general surgeon compared with a survival of $21 \%$ if surgery was performed by a gynecologic oncologist or an experienced gynecologist. Nguyen et al found, in a national survey of 12,316 American women, that the 5-year survival rate for advanced disease was significantly worse if a general surgeon performed the surgery compared with a gynecologic oncologist or a trained gynecologist (18).

In this study, the overall survival rate was approximately the same for category 1 and 2 hospitals but significantly different from the survival rate in category 3 hospitals (Fig. 2). The 5-year survival rate for category 1 and 2 hospitals was $38 \%$ but only $10 \%$ for category 3 hospitals. These results indicate the importance of centralization of the primary cytoreductive surgery, but also the chemotherapy and the general care for patients with ovarian cancer in advanced stages. This has also been demonstrated in studies from Denmark, Finland, and Norway $(4,27,28)$. However, the strongest independent predictive factor for surgical outcome in this study after correction for age was the type of surgeon and for overall survival it was the amount of residual tumor. As the extent of surgery and thus the residual disease is dependent on the tumor biology (stage, histology and grade), which cannot be altered, only the skill of the surgeon and the level of the surgical work can be influenced. Therefore, primary surgery in advanced ovarian cancer should be performed by a gynecologic oncologist or a trained gynecologist and in a hospital with adequate resources for major cancer surgery.

\section{References}

1. Harlan LC, Clegg LX, Trimble EL, et al: Trends in surgery and chemotherapy for women diagnosed with ovarian cancer in the United States. J Clin Oncol 21: 3488-3494, 2003.

2. Aletti GD, Gostout BS, Podratz KC and Cliby WA: Ovarian cancer surgical respectability: Relative impact of disease, patient status, and surgeon. Gynecol Oncol 100: 31-37, 2006.

3. Onda T, Yoshikawa H, Yasugi T, Yamada M, Matsumoto K and Taketani Y: Secondary cytoreductive surgery for recurrent epithelial ovarian carcinoma: proposal for patients selection. $\mathrm{Br}$ J Cancer 92: 1026-1043, 2005.

4. Andersen ES, Knudsen A, Svarrer T, Lund B, Nielsen K, Grove A and Tetsche $\mathrm{M}$ : The results of epithelial ovarian cancer after centralization of primary surgery. Results from North Jutland, Denmark. Gynecol Oncol 99: 552-556, 2005.

5. Berman ML: Future directions in the surgical management of ovarian cancer. Gynecol Oncol 90: 33-39, 2003.

6. Eltabbach GH, Mount SL, Beatty B, Simmons-Arnold L, Cooper K and Morgan A: Factors associated with cytoreducibility among women with ovarian carcinoma. Gynecol Oncol 95: 377-383, 2004.

7. Qayyum A, Coakley FV, Westphalen AC, Hricak H, Okuno WT and Powell B: Role of CT and MR imaging in predicting optimal cytoreduction of newly diagnosed primary epithelial ovarian cancer. Gynecol Oncol 96: 301-306, 2005.
8. Bristow RE, Tomacruz RS, Armstrong DK, Trimble EL and Montz FJ: Survival effect of maximal cytoreductive surgery for advanced carcinoma during the platinum era: A meta-analysis. $\mathbf{J}$ Clinical Oncol 20: 1248-1259, 2002.

9. Dowdy SC, Mullany SA, Brandt KR, Huppert BJ and Cliby WA: The utility of computed tomography scans in predicting suboptimal cytoreductive surgery in women with advanced ovarian carcinoma. Cancer 101: 346-352, 2004.

10. Chi DS, Venkatraman ES, Masson V and Hoskins WJ: The ability of preoperative serum Ca-125 to predict optimal primary tumor cytoreduction in stage III epithelial ovarian carcinoma. Gynecol Oncol 77: 227-231, 2000.

11. Memarzadeh S, Lee SB, Berek JS and Farias-Eisner R: Ca 125 levels are a weak predictor of optimal cytoreductive surgery in patients with advanced epithelial ovarian carcinoma. Int $\mathbf{J}$ Gynecol Cancer 13: 120-124, 2003.

12. Berchuck A, Iversen ES, Lancaster JM, et al: Prediction of optimal versus suboptimal cytoreduction of advanced-stage serous ovarian cancer with the use of microarrays. Am J Obstet Gynecol 190: 910-925, 2004.

13. Hoskins WJ, Bundy BN, Thigpen JT and Omura GA: The influence of cytoreductive surgery on recurrence-free interval and survival in small volume stage III epithelial ovarian cancer: a Gynecologic Oncology Group Study. Gynecol Oncol 47: 159-166, 1992.

14. Kaplan EL and Meier P: Nonparametric estimation from incomplete observations. Am Stat Assoc J 58: 457-481, 1958.

15. Cox DR: Regression models and life tables. J R Statist Soc 34: 187-220, 1972.

16. Lambert HE, Gregory WM, Nelstorp AE and Rustin GJS: Longterm survival in 463 women treated with platinum analogs for advanced epithelial carcinoma of the ovary: life expectancy compared to women of an age-matched normal population. Int $\mathbf{J}$ Gynecol Cancer 14: 772-778, 2004.

17. Averette HE, Hoskins W, Nguyen HN, et al: National survey of ovarian carcinoma: I. A patient care evaluation study of the American College of Surgeons. Cancer 71: 1629-1638, 1993.

18. Nguyen HN, Averette HE, Hoskins W, et al: National survey of ovarian carcinoma: Part V. The impact of physician's speciality on patient's survival. Cancer 72: 3663-3670, 1993.

19. Chi DS, Franklin CC, Levine DA, et al: Improved optimal cytoreduction rates for stages IIIC and IV epithelial ovarian, fallopian tube and primary peritoneal cancer: a change in surgical approach. Gynecol Oncol 94: 650-654, 2004.

20. Covens AL: A critique of surgical cytoreduction in advanced ovarian cancer. Gynecol Oncol 78: 269-374, 2000.

21. Naik R, Nordin A, Cross PA, et al: Complete cytoreduction: Is epithelial ovarian cancer confined to the pelvis biologically different from bulky abdominal disease? Gynecol Oncol 78: 176-180, 2000.

22. Junor EJ, Hole DJ, McNutly L, Mason M and Young J: Specialist gynecologists and survival outcome in ovarian cancer: a Scottish national study of 1866 patients. Br J Obstet Gynaecol 106: 1130-1136, 1999.

23. Kaern J, Aghmesheh M, Nesland JM, Danielsen HE, Sandstad B, Friedlander $\mathrm{M}$ and Tropé C: Prognostic factors in ovarian carcinoma stage III patients. Can biomarkers improve the prediction of short- and long-term survivors? Int J Gynecol Cancer 15: 1014-1022, 2005.

24. Engel J, Eckel R, Schubert-Fritschle G, et al: Moderate progress for ovarian cancer in the last 20 years: prolongation of survival, but no improvement in the cure rate. Eur J Cancer 38: 2435-2445, 2002.

25. Chi DS, Liao JB, Leon LF, et al: Identification of prognostic factors in advanced epithelial ovarian carcinoma. Gynecol Oncol 82: 532-537, 2001.

26. Polverino G, Parazzini F, Stellato G, Scarfone G, Cipriani S and Bolis G: Survival and prognostic factors of women with advanced ovarian cancer and complete response after a carboplatin-paclitaxel chemotherapy. Gynecol Oncol 99: 343-347, 2005.

27. Kumpulainen S, Grénman S, Kyyronen P, Pukkala E and Sankila R: Evidence of benefit from centralized treatment of ovarian cancer: a nationwide population-based survival analysis in Finland. Int J Cancer 102: 541-544, 2002.

28. Tingulstad S, Skjeldestad FE and Hagen R: The effect of centralization of primary surgery on survival in ovarian cancer patients. Obstet Gynecol 102: 499-505, 2003. 